\title{
Backward masking as a function of interstimulus distance
}

\author{
R. LEVINE, R. DIDNER AND N. TOBENKIN 1 \\ NEW YORK UNIVERSITY
}

A study was performed to determine the effect of interstimulus distance on visual backward masking. Utilizing the Method of Limits, stimuli were presented by means of a three field tachistoscope. When interstimulus distances were small, masked elements were not perceived at all. As distances increased a gradient effect was observed.

Phenomena similar to backward masking were first reported as metacontrast (Woodworth \& Schlosberg, 1954). Traditionally, there have been two conditions necessary for metacontrast to take place: (1) The total time duration between the onset of the first (masked) figure, and the termination of the second (masking) figure must be on the order of $150 \mathrm{msec}$ including the interstimulus time. The interstimulus time is the time interval between the termination of the first figure and the onset of the second. (2) The outer border of the first figure must be framed by the second.

Recently it has been found that only the first of the above conditions is necessary if masking is to occur (Fraisse, 1966; Toch, 1956; Mayzner et al, 1966,1967). Specifically, in the above studies, a stimulus element which was followed in time by two other elements, appearing on either side of the first (masked) element, was either misperceived, poorly perceived, or not perceived at all. Some parameters, reported as having a significant effect on backward masking were presentation or display input order (Mayzner et al, 1966), intercontour distance (Streicher \& Pollack, 1967), interstimulus time (Mayzner et al, 1966; Fraisse, 1966; Toch, 1956; Raab, 1963).

The present study deals with distance between stimulus elements as it affects backward masking.

\section{Method}

A three field tachistoscope (Scientific Prototype Model GB) was used for visual presentations of two stimulus fields and one blank field. The luminance was equal for all three fields and for all conditions. Stimuli consisted of upper case letters $1 / 4$ in. high from Letra set Sheet No. 129.

The blank field contained no fixation point for all conditions. The experimental conditions consisted of presenting CHAIR with $C A R$ in Field 1 and $H I$ in Field 2. The three fields were presented in the order 2 - blank - 1 (1.e., H I - blank - C A R) for all experimental conditions such that Fields 1 and 2 were on for 15 msec each, and the blank fleld for a length of time (interstimulus time) determined for each $S$ by a pllot study described below.
The interstimulus distance (i.e., distance between letters) was a multiple of letter height ( $1 / 4 \mathrm{in}$.). The distances were 0 (with edges adjacent), $1 / 4,1 / 2,1$, 2, and 4 times the letter height. Two types of control conditions were used: (1) E T K and Z M R were interspersed into the presentation order to reduce response perseveration. In each case the middle letter was presented in Field 2 and the outer letters in Field 1. (2) $H I$ and $C A R$ were included to check on the reliability of Ss' $^{\prime}$ reports. Each was presented on one field. The order of presentation followed the method of limits and is given in Table 1.

A pllot study was run for each $\mathrm{S}$ prior to the experiment to establish an interstimulus time for which backward masking took place. The method employed was similar to the method of limits. The letters used in the pilot study were $N E U$ with $E$ in Field 2 and $\mathrm{N} U$ in Field 1, presented in the order: Field 2 - blank - Field 1.

Ss were six females between the ages of 18 and 26 and naive as to the purpose of the experiment. Ss were told to report exactly what they saw after three repetitions for each condition. If an $S$ was uncertain as to what she perceived, she was given an additional three repetitions of the same condition.

\section{Results and Discussion}

The mean perception of masked elements, in percent, was arrived at in the following manner: If the $S$ reported seeing nothing in the positions where the blanked letters were presented, the response was categorized as $0 \%$ perception. If $S$ reported seeing one of the blanked letters, or one or two unclear elements in the blanked letter positions, or two letters which were not $H$ and $I$, the response was categorized as $50 \%$ perception. If $S$ reported seeing both $H$ and $I$ the response was categorized as $100 \%$ perception. The mean perception of masked elements is shown in Table 2.

Table 1 Presentation order of conditions

\begin{tabular}{cc}
\hline Distance & Stimulus \\
0 & CHAIR \\
0 & ETK \\
$1 / 4$ & CHAIR \\
& HI \\
$1 / 2$ & CHAIR \\
2 & ZMR \\
1 & CHAIR \\
& CAR \\
2 & CHAIR \\
4 & CHAIR \\
\hline
\end{tabular}


Table 2 Mean perception of masked elements in percent

\begin{tabular}{lllrrrr}
\hline & \multicolumn{5}{c}{ Distance } \\
& 0 & $1 / 4$ & $1 / 2$ & 1 & 2 & 4 \\
\hline S1 & 00 & 06 & 44 & 100 & 94 & 100 \\
S2 & 00 & 00 & 00 & 13 & 69 & 75 \\
S3 & 00 & 13 & 43 & 63 & 94 & 100 \\
S4 & 25 & 56 & 69 & 100 & 100 & 100 \\
S5 & 00 & 25 & 75 & 100 & 100 & 100 \\
S6 & 06 & 13 & 50 & 69 & 100 & 100 \\
\hline
\end{tabular}

For all Ss the control conditions, $H$ I and C A R, were perceived $100 \%$ correctly, and no elements or letters of any kind which were not presented were reported. For all experimental conditions the masking elements (C A R) were perceived correctly.

Note that the performance of all Ss was similar, in that with the the minimum distance between letters the maximum mean percentage of masking (corresponding to 0 on Table 2) was obtained. Also, as the interstimulus distance increased, the mean percentage of masking decreased, stabllizing at near perfect perception of all letters.

The most startling effect of this study is that in some conditions the Ss reported not having perceived the masked elements at all.

The results are different from those of Toch (1956) who stated that contiguity was essential to blanking, and agree with those of Streicher \& Pollack (1967) and Raab (1963) who stated that masking of the center element decreased as the flanking stimuli are spatially removed from it. However, masking did not decrease rapidly as Raab (1963) stated, but followed a gradient function.

In performing the pilot study, it was noticed that the time factors, specifically the interstimulus and total time (on the order of $70 \mathrm{msec}$ ) agreed with those found by Fraisse (1966). Toch (1956), on the other hand, using a mechanical timing device and incandescent lamps, obtained an optimal time of 260 msec with an interstimulus time of $160 \mathrm{msec}$. The difference between electronic vs mechanical timing devices, and gas discharge vs incandescent lamps, may account for the discrepancy of times reported.

\section{References}

FRAISE, P. Visual perceptive simultaneity and masking of letters successively presented. Percept. \& Psychophys, 1966, 1, 285-287.

MAYZNER, M., TRESSELT, M. E., \& COHEN, A. Preliminary findings on some effects of very fast sequential input rates on perception. Psychon. Sci, 1966, 6, 513-514.

MAYZNER, M., TRESSELT, M. E., \& COHEN, A. Further findings on some effects of very fast sequential input rates on perception.Psychon. Sci, 1967, 7, 281-282.

RAAB, D. H. Backward masking. Psychol. Bull, 1963, 60, 118-129. STREICHER, H., \& POLLACK, R. Backward figural masking as a function of intercontour distance. Psychon. Sci, 1967, 7, 69-70.

TOCH, H. H. Perceptual elaboration of stroboscopic presentations. Amer. J. PsychoL, 1956, 69, 345-358.

Note

1. This study was performed as part of a course in graduate Research Methods given by the N.Y.U. Department of Industrial Engineering and Operations Research. Special thanks to M. S. Mayzner, instructor of the above course. 